\title{
Effect of Deposition Temperature on the Physical Performance of $\mathrm{n}-\mathrm{ZnO} / \mathrm{p}-\mathrm{Si}$ Heterojunction
}

\author{
Yasir Hussein Mohammed
}

Department of Physics, College of Education for Pure Science, University of Mosul, Mosul, Iraq

Email: yasir.h.m@uomosul.edu.iq

(Received August 25, 2019; Accepted November 15, 2019; Available online June 01, 2020)

DOI: 10.33899/edusj.2019.126043.1017, (C) 2020, College of Education for Pure Science, University of Mosul.

This is an open access article under the CC BY 4.0 license (http://creativecommons.org/licenses/by/4.0/).

\begin{abstract}
Comparative study of the physical characteristics of $\mathrm{n}-\mathrm{ZnO} / \mathrm{p}-\mathrm{Si}$ heterojunction diode has been done as a function of deposition temperature in the range of $300-600{ }^{\circ} \mathrm{C}$. Transparent conducting (TC) Zinc Oxide ( $\mathrm{ZnO}$ ) thin films were deposited by atmospheric pressure chemical vapor deposition (APCVD) technique on the $\mathrm{p}$-Si(100) and glass substrates. Also, the influences of different deposition temperature on the morphology and optical properties of ZnO films were studied. Both the average surface roughness (from 62.8 to $18.8 \mathrm{~nm}$ ) and the root mean square (from 78.2 to $24 \mathrm{~nm}$ ) of $\mathrm{ZnO}$ films were decreased with the increase in the deposition temperature. Optical transmittance measurement results exhibited good transparency within the visible wavelength range for the films prepared at a temperature above $400{ }^{\circ} \mathrm{C}$. The current-voltage (I-V) characteristics of the heterojunction diodes exhibited rectification behavior and depend on the deposition temperature. The electrical parameters of the $\mathrm{n}-\mathrm{ZnO} / \mathrm{p}$-Si heterojunctions were also affected by the deposition temperature. The diodes prepared at a temperature above $400{ }^{\circ} \mathrm{C}$ were possessed lower reverse saturation current and high rectification ratio compared to those fabricated at a relatively lower temperature such as $300^{\circ} \mathrm{C}$ or $400{ }^{\circ} \mathrm{C}$. Such low a temperature grown $\mathrm{n}-\mathrm{ZnO} / \mathrm{p}$-Si heterojunction diodes with lower reverse saturation current could be suitable for photo-detection applications.
\end{abstract}

Keywords: Heterojunction diodes; electrical characteristics; deposition temperature; chemical vapor deposition.

$$
\begin{aligned}
& \text { تأثير درجة حرارة الترسيب على الأداء الفيزيائي للمفرق المتباين (n-ZnO/p-Si) } \\
& \text { ياسر حسين محمد } \\
& \text { قسم الفيزياء، كلية التربية للعلوم الصرفة، جامعة الموصل، الموصل، العراق }
\end{aligned}
$$

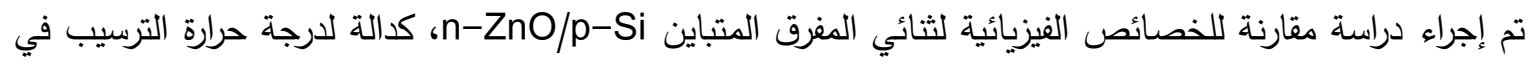

$$
\begin{aligned}
& \text { المدى (Co Co0-300). أغشية أوكسيد الزنك (ZnO) الرقيقة الموصلة الثفافة تم ترسيبها بتقنية الترسيب البخاري الكيميائي }
\end{aligned}
$$


عند الضغط الجوي الاعتيادي (APCVD) على أرضيات من السليكون (p-Si(100) و الزجاج. كذلك تمت دراسة تأثير تغيير

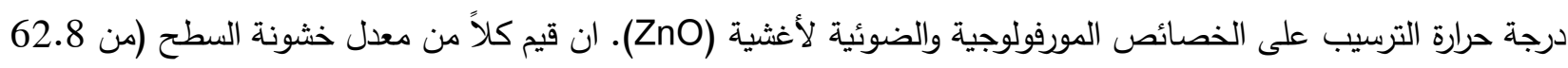

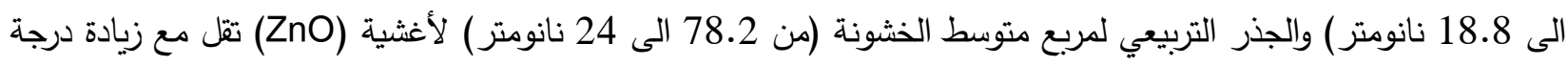

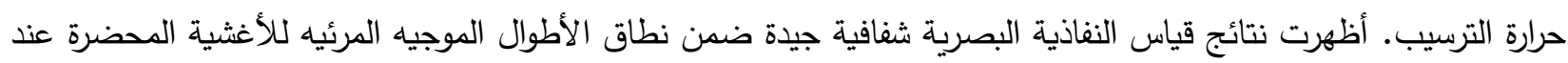

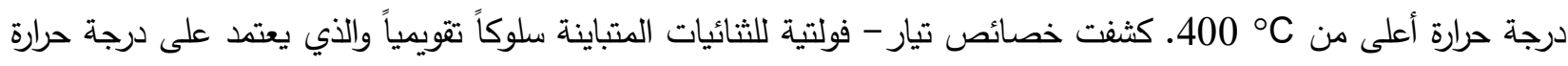

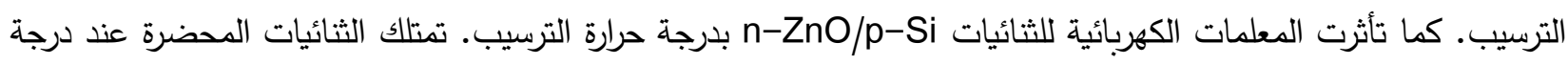
حرارة أعلى من Co 400 تيار تثبع عكسي منخفض، ونسبة تقويم عالية مقارنة بتلك المصنعة عند درجة حرارة منخفضة نسبيًا

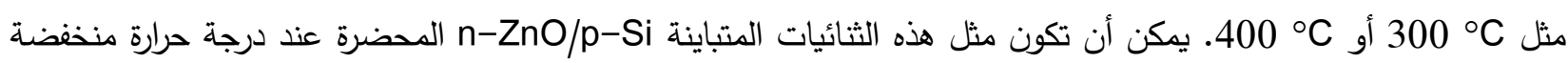
والتي تمتلك تيار تشبع عكسي منخفض مناسبة لتطبيقات الكثف الضوئي.

الكلمات المفتاحية: الثنائيات المتباينة، الخصائص الكهربائية، درجة حرارة الترسيب، الترسيب البخاري الكيميائي.

المقدمة

يعتبر أوكسيد الزنك مادة الكترو بصرية شفافة واعدة بسبب خصائصه الألكترونية والضوئية الفريدة من نوعها [1]. إذ

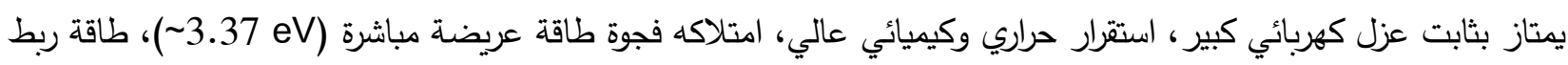

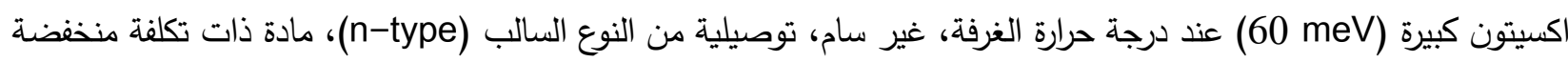

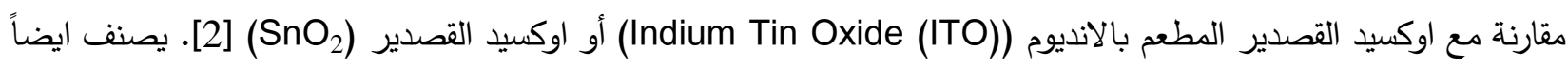
ضمن مجموعة الأكاسيد الموصلة الثفافة (Transparent Conductive Oxide (TCO)، والتي التي تمتلك انعكاسية جيدة في المنطقة تحت الحمراء القرببة ونفاذية عالية في المنطقة المرئية. إن هذه الخصائص مكنت من استخدامه بشكل مؤثر في التطبيقات

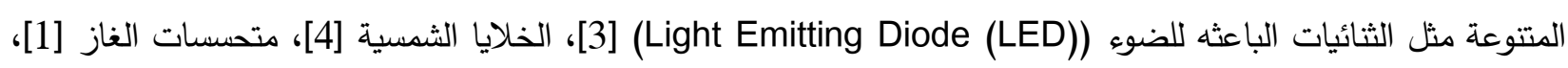

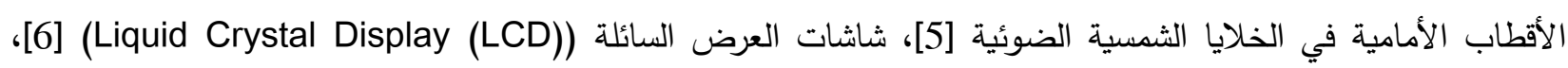
كواشف الأشعة فوق البنفجية [7]، بالاضافة الى التطبيقات الاككترونية كترانزستورات [8, 9]. لذا فهو يعد اليوم مفتاحاً اساسياً في عمليات تصنيع مختلف النبائط الأكترو بصرية [10]. عموماً، يتم ترسيب أغشية (n-ZnO) الرقيقة على أرضيات متنوعة الرئية

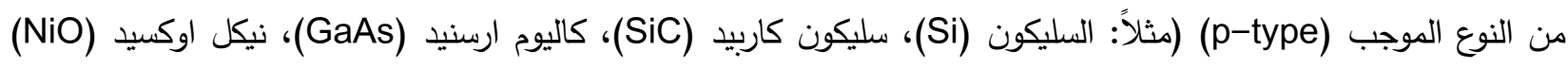

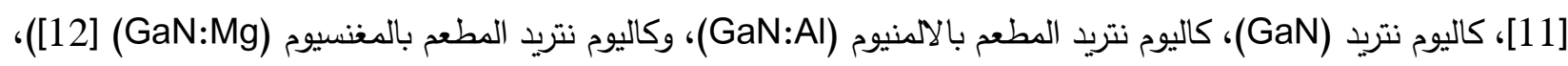

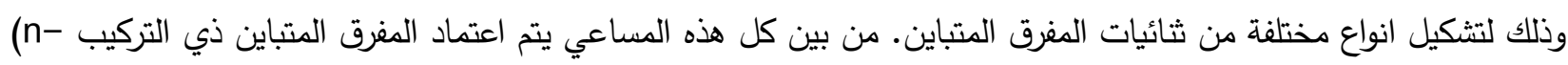
ZnO/p-Si)

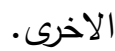

استخدمت عدة طرق لتحضير أغشية (ZnO) الرقيقة، منها تقنية الاستئصال بالليزر النبضي Pulsed Laser) [13blation)

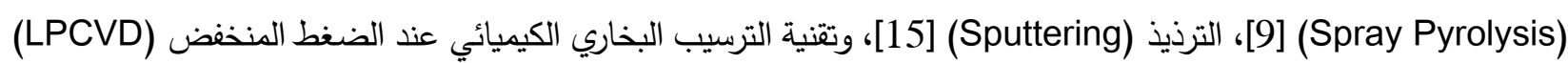
[4]. إن تقنية الترسيب البخاري الكيميائي (CVD) يمكن ان تعمل اما في الضغط المنخفض أو الجوي [16] وتمتاز بكونها ذات تكلفة منخفضة لا تحتاج الى عمليات تفريخ عالية (14 Torr اقتصادية مقارنة مع تقنيات الترسيب الاخرى، وامكانية فائقة في تصنيع (توليف) المواد النانوية ذات الابعاد المنخفضة (احادية 
الابعاد (1D) وثنائية الابعاد (2D) (17D) هي عملية ترسيب كيميائي تثكل تقاعلاً في الطور الغازي قرب قاعدة الترسيب الساخنة لتكون غثاء صلب [18].

أجريت دراسات متتوعة على مادة (ZnO) بشكل غشاء رقيق ودرست إمكانية الاستفادة منه في كثير من النطبيقات

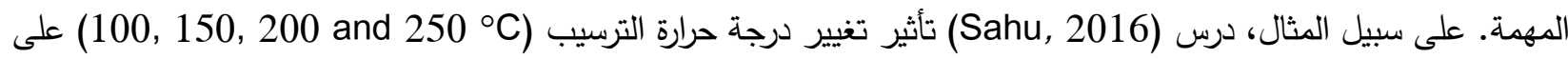

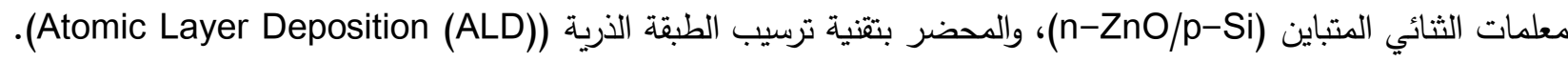

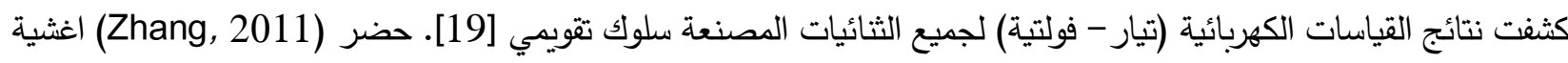

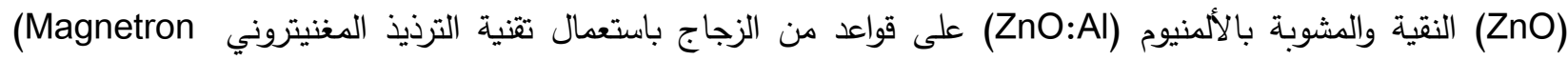
Sputtering) دالة لدرجة حرارة الترسيب. اظهرت نتائج القياسات البصرية بان جميع الاغشية تمتلك نفاذية بصرية عالية بحدود (85\% ) [20]. إن الاهتمام بتطوير أغشية رقيقة ذات خصائص فيزيائية متميزة قد ازداد بصورة هائلة نتيجة النمو السريع للتطبيقات التهية

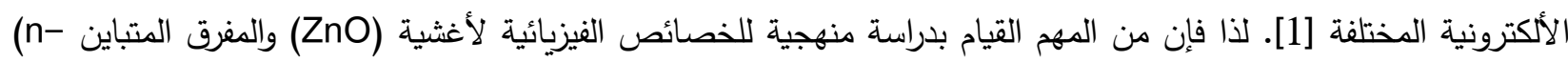

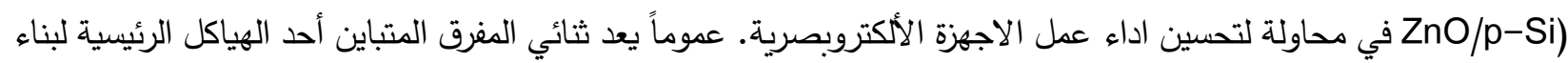

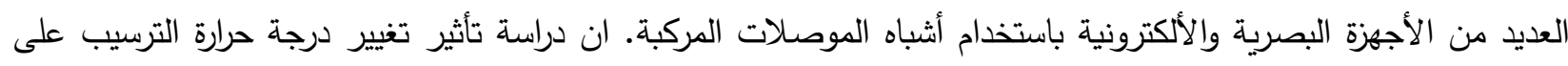

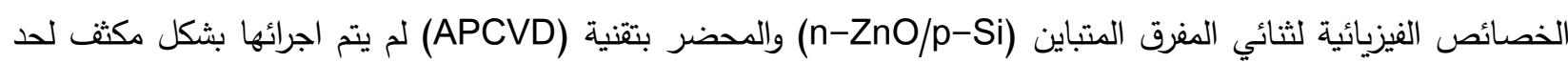

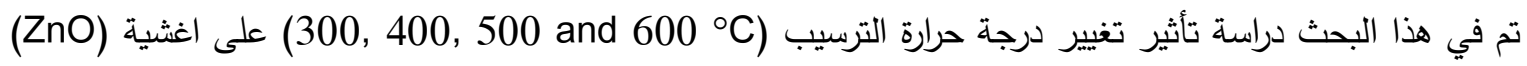

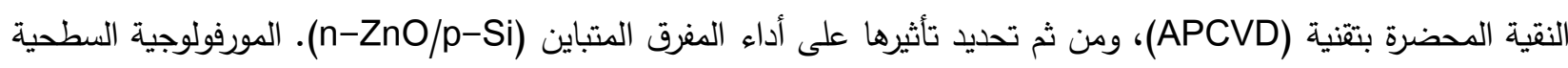
للأغشية المحضرة (ZnO/p-Si) تمت دراستها باستخدام مجهر القوة الذرية (Atomic Force Microscope-AA3000). القياسات البصرية للأغشية الرقيقة (ZnO/Glass) اشتملت على قياس النفاذية والأمتصاصية ضمن مدى الأطوال الموجية

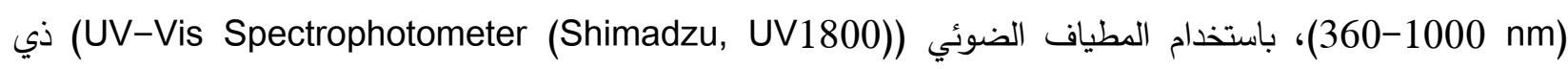
الحزمتين. كذلك تم تقييم ومقارنة الأداء الكهربائي للثنائي المتباين (n-ZnO/p-Si) باستخدام دائرة تيار - فولتية المتوالية.

التقنية العملية تم في هذا البحث تحضير أغشية (ZnO) الرقيقة عند درجات حرارة ترسيب مختلفة 600 (300, 400, 500 and

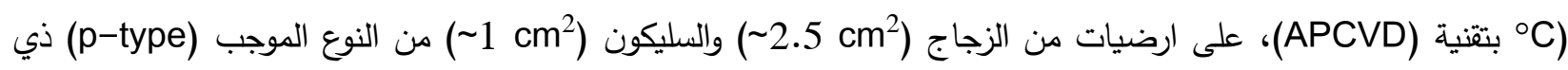
الاتجاهية (100). اذ نظفت هذه الأرضيات بشكل جيد للتخلص من اية مواد عالقة فيها وذلك بغسلها بمحلول الأسيتون،

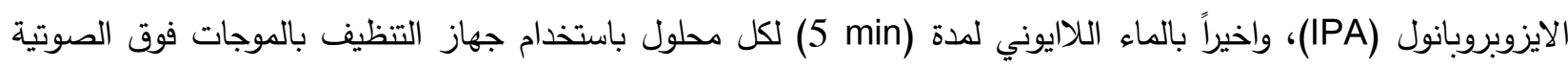
(Ultrasonic Cleaner)

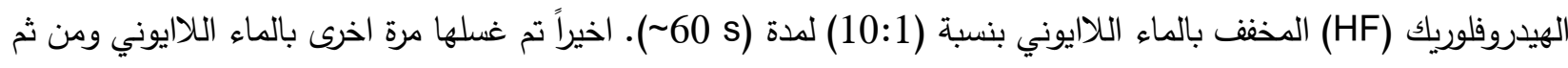
تجفف بالهواء الحار وتخزن في حاوية مفرغة من الهواء.

تم تصنيع جميع الثنائيات المتباينة (n-ZnO/p-Si)، من خلال ترسيب طبقة رقيقة من الالمنيوم النقي (100) (99.9\% )

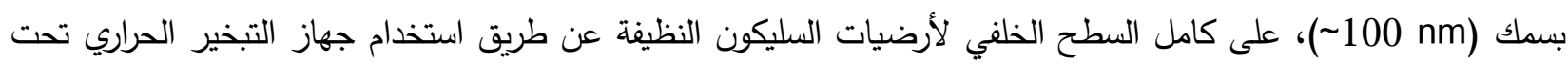

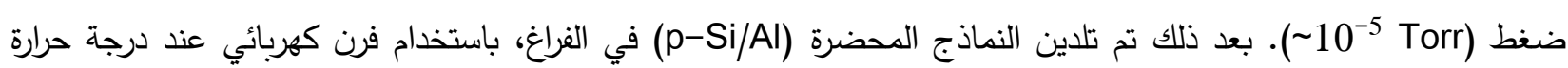




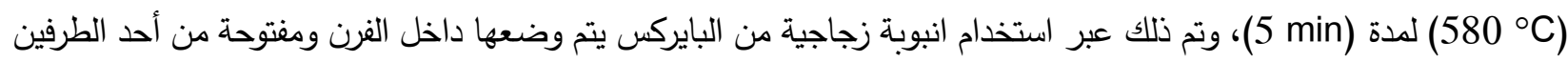

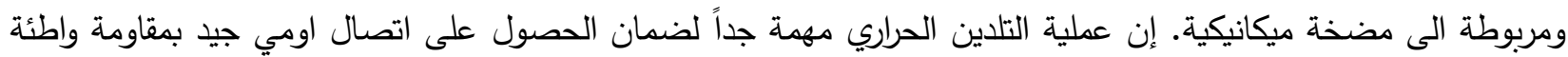
في نبائط اشباه الموصلات. بعدها تم تثبيت العينات (الزجاج و (p-Si/Al)) على حامل، ومن ثم يتم ادخال الحامل داخل انبوبة

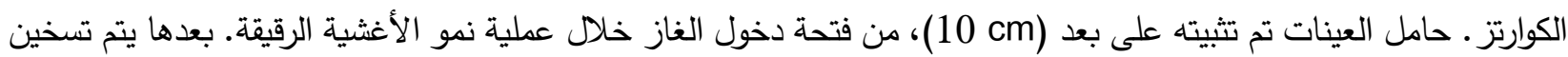

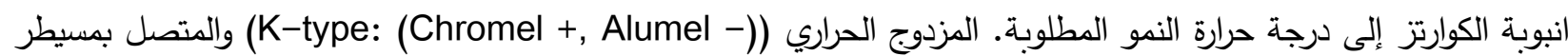
حراري (SG-642) تم استخدامهما للقياس والسيطرة على درجة حرارة الأرضيات بشكل دقيق. اغشية (ZnO) الرقيقة تم ترسيبها لمدة (15in min)، على السطح الأمامي للعينات (الزجاج و (AP-Si/Al)) بتقنية (APCVD)، عند درجات حرارة ترسيب مختلفة. إن أغشية (ZnO) الرقيقة تم تحضيرها من خلال استخدام مادة خلات الزنك المائية [Cn(CH كمصدر لعنصر الزنك. حيث تم وضع كمية مقاسة (2.195 gm) من خلات الزنك المائية في بودقة التبخير لتبدأ عملية التسخين إلى درجة حرارة الذوبان ومن ثم التبخر عند درجة حرارة تتراوح (م80 C C

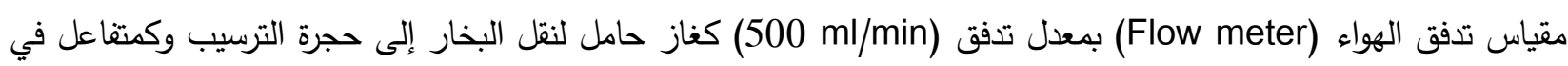
عملية الأكسدة داخلها. إن عملية طرد الأبخرة قبل دخولها حجرة الترسيب باتجاه وحدة معالجة الغازات بواسطة صمام التوجيه لمدة (Reversible Valve)

الثكل (1) يعرض مخطط توضيحي لتقنية (APCVD)، والتي تتكون بشكل أساسي من وحدة التبخير (أنتاج الغاز) ووحدة الترسيب. المعادلة الآتية تبين التفاعل الكيميائي الذي يحدث اثناء عملية تكوين اغشية (ZnO).

$2 \mathrm{Zn}\left(\mathrm{CH}_{3} \mathrm{COO}\right)_{2} \cdot 2 \mathrm{H}_{2} \mathrm{O} \stackrel{\Delta}{\rightarrow} 2 \mathrm{ZnO}+3 \mathrm{CO}_{2} \uparrow+2 \mathrm{CH}_{4} \uparrow+2 \mathrm{H}_{2} \uparrow+2 \mathrm{H}_{2} \mathrm{O} \uparrow$

أخيراً تم ترسيب اقطاب دائرية الثكل، ذات اقطار (2 mm ) بسمك (100 nm) من مادة الألمنيوم على السطح العلوي لأغشية (ZnO) المنماءة من خلا استخدام قناع معدني بتقنية التبخير الحراري.

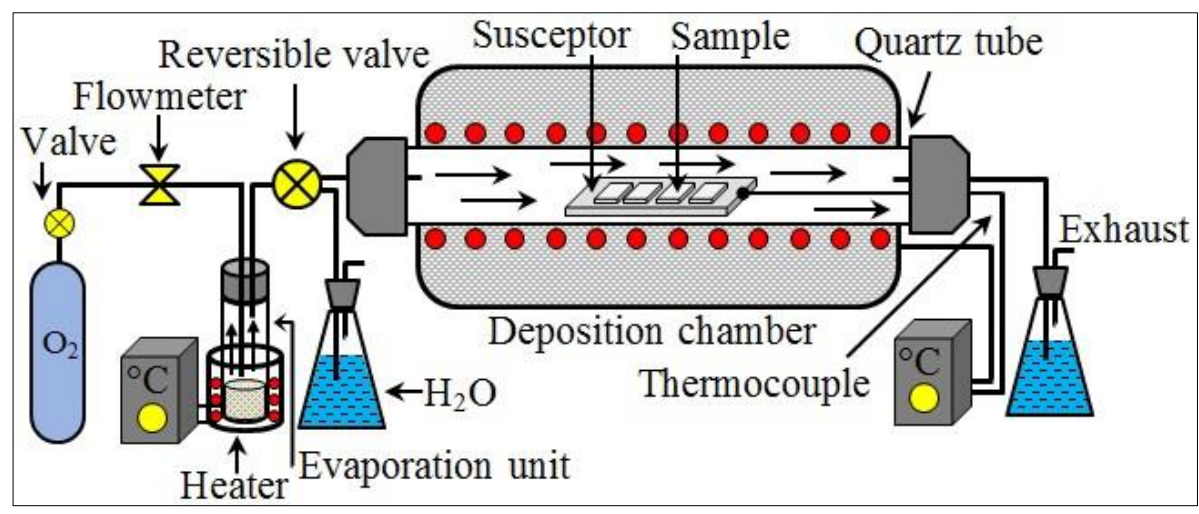

الثكل (1): مخطط توضيحي لمنظومة الترسيب البخاري الكيميائي عند الضغط الجوي الاعتيادي (APCVD).

الثكل (2) يصور مخطط توضيحي للمقطع العرضي للثنائيات المتباينة المصنعة. لتوصيل الثنائيات المتباينة المصنعة بمنظومة قياس تيار - فولتية، تم لصق أسلاك نحاسية رفيعة على نقطة الاتصال (الأقطاب) باستخدام معدن الأنديوم. 


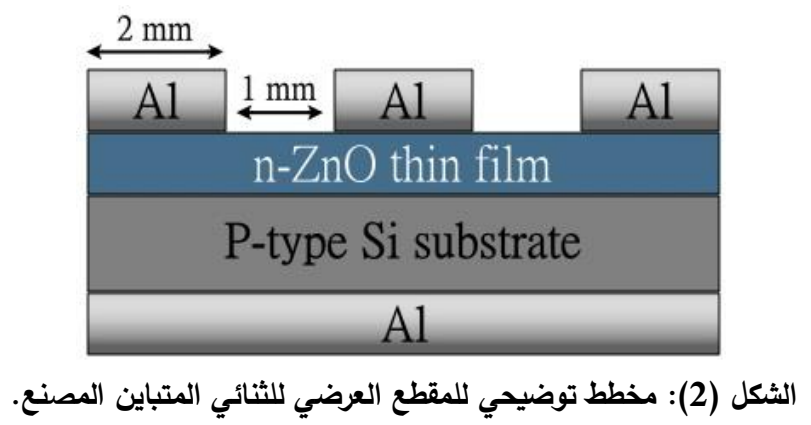

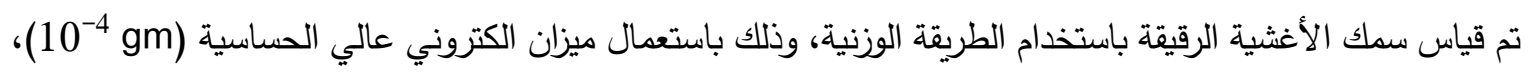
حيث تم وزن الأرضية قبل وبعد عملية الترسيب، وعن طريق أيجاد فرق الكتلة وبمعرفة كثافة مادة الغشاء ومساحته يمكن أيجاد السمك وفق المعادلة الاتية [21]:

$\mathrm{t}(\mathrm{cm})=\frac{\Delta \mathrm{m}(\mathrm{gm})}{\mathrm{A}\left(\mathrm{cm}^{2}\right) \rho\left(\mathrm{gm} / \mathrm{cm}^{3}\right)}$

حيث ان (t) سمك الغشاء المحضر، (m) كتلة مادة الغشاء، (A) مساحة الغشاء و (م) كثافة مادة غشاء (ZnO). يتراوح سمك الأغشية المحضرة ضمن المدى (conm (680-390 ).

النتائج والمناقشة

لأجل دراسة تضاريس سطوح الأغشية المحضرة ومدى تأثير تغيير درجة حرارة الترسيب عليها، تم توظيف مجهر القوة

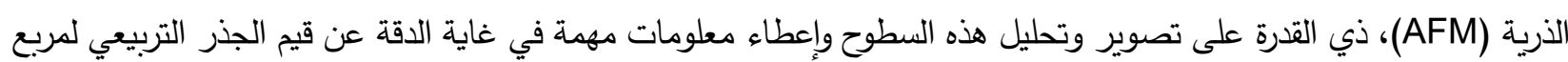

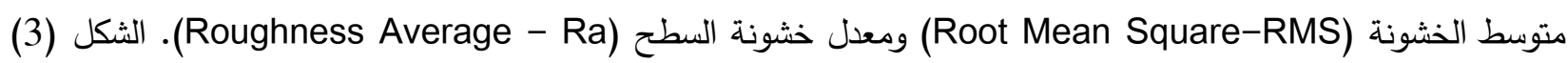
يظهر صور مجهر القوى الذرية ثنائية الأبعاد لأغشية (ZnO) المحضرة على أرضيات من السليكون عند درجات حرارة ترسيب

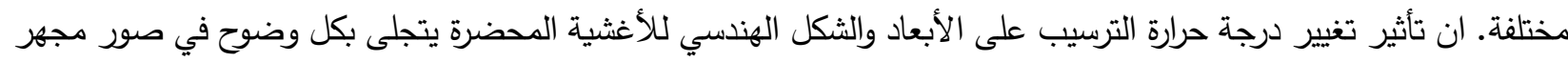
القوى الذرية (الثكل 3). كذلك تظهر الصور تتاقص قيم (RMS) و (Ra) للأغشية المحضرة بزيادة درجة حرارة الترسيب. قيم

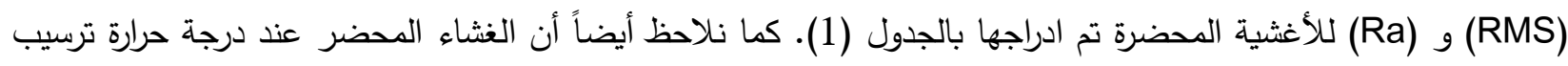

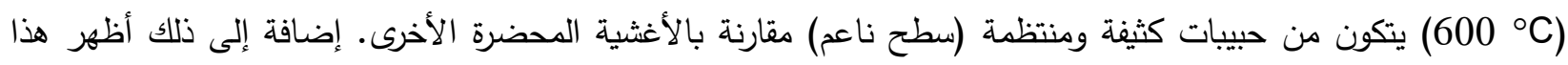

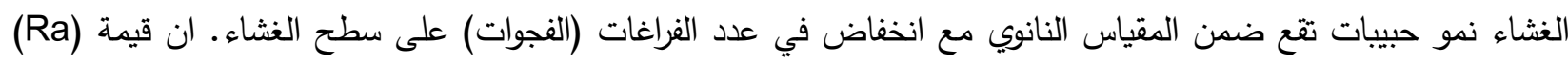

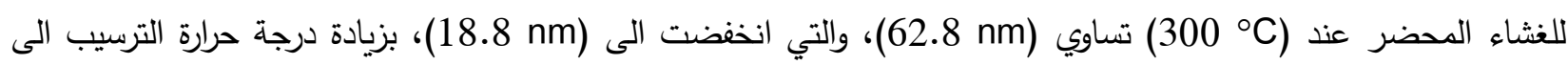
(600) ( 600 أن زيادة نعومة السطح مع زيادة درجة حرارة الترسيب يمكن أن يعزى الى ان الذرات تمتلك طاقة كافية لإعادة الترتيب لتثكيل سطح ناعم عند درجة حرارة ترسيب عالية [22]. 

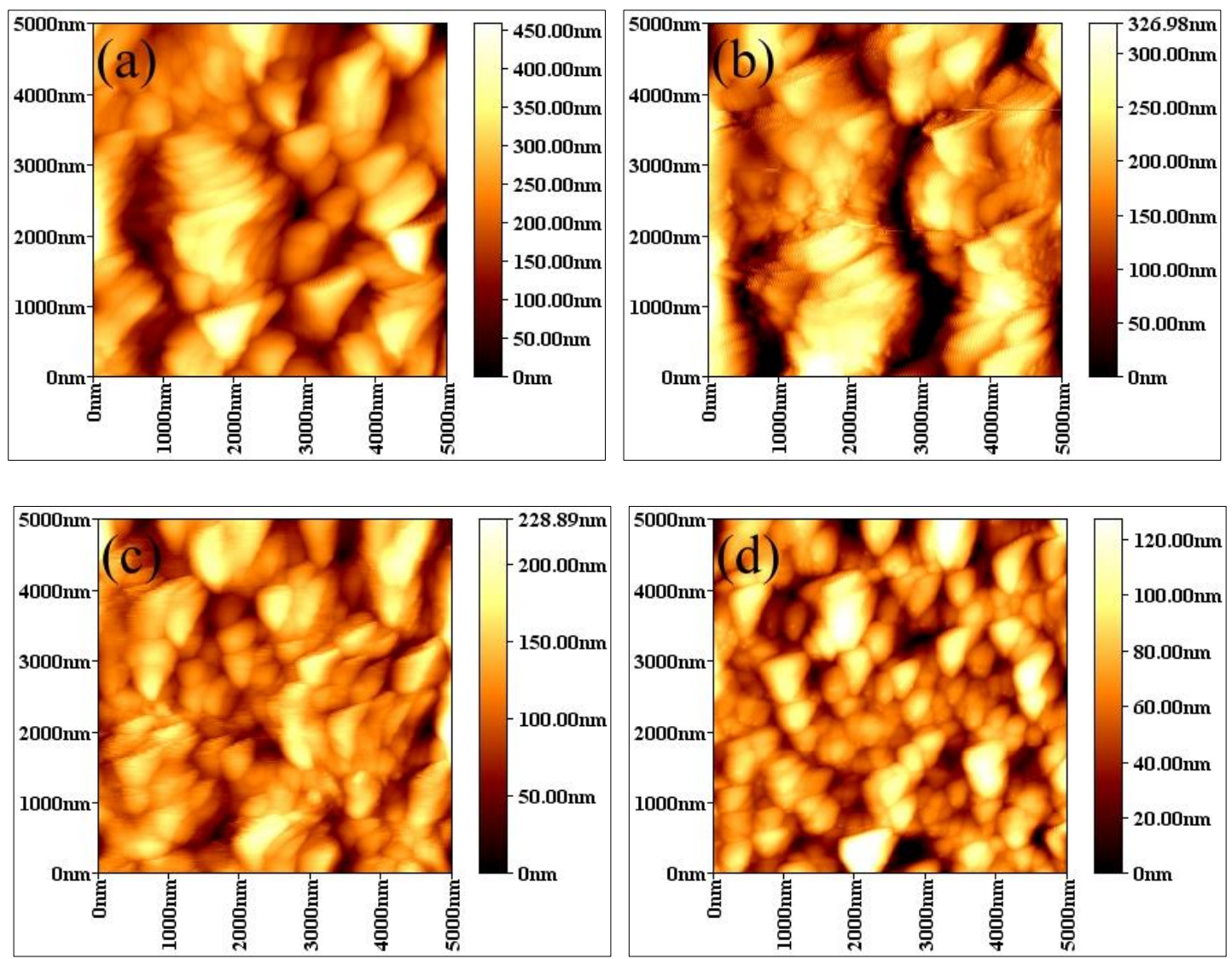

الثكل (3): يعرض صور مجهر القوة الذرية لأغثية (ZnO) المحضرة عند درجات حرارة ترسيب مختلفة

.(d) $600{ }^{\circ} \mathrm{C}$, (c) $500{ }^{\circ} \mathrm{C}$ ،(b) $400{ }^{\circ} \mathrm{C}$ ،(a) $300{ }^{\circ} \mathrm{C}$ 
Journal of Education and Science (ISSN 1812-125X), Vol: 29, No: 2, 2020 (118-132)

الجدول (1): المعلمات المورفولوجية، الضوئية والكهربائية للنماذج المحضرة.

\begin{tabular}{c|c|c|c|c|c|c|c|c}
\hline $\begin{array}{c}\text { Deposition } \\
\text { temperature } \\
\left({ }^{\circ} \mathrm{C}\right)\end{array}$ & $\begin{array}{c}\mathrm{Ra} \\
(\mathrm{nm})\end{array}$ & $\begin{array}{c}\mathrm{RMS} \\
(\mathrm{nm})\end{array}$ & $\begin{array}{c}\mathrm{E}_{\mathrm{opt}} \\
(\mathrm{eV})\end{array}$ & $\mathrm{RR}$ at $\pm 2 \mathrm{~V}$ & $\begin{array}{c}\mathrm{R}_{\mathrm{s}} \\
(\mathrm{k} \Omega)\end{array}$ & $\begin{array}{c}\mathrm{I}_{\mathrm{o}} \\
(\mathrm{nA})\end{array}$ & $\eta$ & $\phi_{\mathrm{b}}(\mathrm{eV})$ \\
\hline 300 & 62.8 & 78.2 & 3.26 & 160 & 2.38 & 1.23 & 3.41 & 0.825 \\
400 & 57.5 & 71.6 & 3.28 & 264 & 2.07 & 9.68 & 3.14 & 0.772 \\
500 & 28.2 & 35.4 & 3.3 & 445 & 1.73 & 21.02 & 2.43 & 0.752 \\
600 & 18.8 & 24 & 3.35 & 1085 & 0.86 & 30.51 & 2.19 & 0.742 \\
\hline
\end{tabular}

تضمنت الخواص البصرية دراسة تأثير تغيير درجة حرارة الترسيب (300, 400, 500 and 600 (300)، على الخواص البصرية لأغشية (ZnO). إذ تضدنت الخواص البصرية قياس ودراسة كل من اطياف النفاذية، الامتصاصية والانعكاسية. الثكل (4) يوضح أطياف النفاذية الضوئية لأغشية (ZnO) الرقيقة المحضرة على أرضيات من الزجاج عند درجات حرارة ترسيب مختلفة. بينت هذه النتائج أن هناك زيادة واضحة في قيم النفاذية الضوئية بوصفها دالة للطول الموجي مع زيادة درجة حرارة الترسيب والتي يقابلها نقصان في قيم الامتصاصية الضوئية (الثكل (5)) ولجميع درجات الحرارة أيضا. يمكن ملاحظة أن أغشية (ZnO)، تمتلك معدل نفاذية يقدر بحوالي (70\% ) عند درجة حرارة (C C 300)، وتزداد هذه القيمة لتصل الى معدل (95\% ) عند درجة حرارة (Co0 600)، ضمن منطقة الطيف المرئي والمنطقة تحت الحمراء القريبة، مع وجود نفاذية واطئة جداً في منطقة الأشعة فوق البنفجية والتي تزداد بشكل حاد عند القيمة (400 nm-380)، وتسمى هذه المنطقة بحافة الامتصاص الأساسية. إن طيف النفاذية لجميع الأغشية أظهر حافة امتصاص حادة في منطقة الاشعة فوق البنفجية وهذا يدل على الامتصاص العالي للفوتونات الساقطة على الغشاء في هذه المنطقة من الطيف الكهرومغناطيسي. كذلك نلاحظ من الثكل (4) وجود ازاحة في حافة الامتصاص الأساسية باتجاه الأطوال الموجية القصيرة (الطاقات العالية) مع زيادة درجة حرارة الترسيب. أن هذه الأزاحة في حافة الامتصاص البصرية، والتي أدت بدورها إلى زيادة في فجوة الطاقة البصرية لأغشية (ZnO)، يمكن أن تكون بسبب تأثير بورشتن - موس (Burstein-Moss effect) [23]. كنلك كثفت الأغشية المحضرة عند درجات حرارة اكبر من Co 400 عن وجود تذبذب في طيف النفاذية الضوئية (الثكل (4)). إن هذه الظاهرة يمكن أن تعزى الى التحسن في التجانس الهيكلي والبلوري للأغثية الرقيقة مع زيادة درجة حرارة الترسيب [24]. 


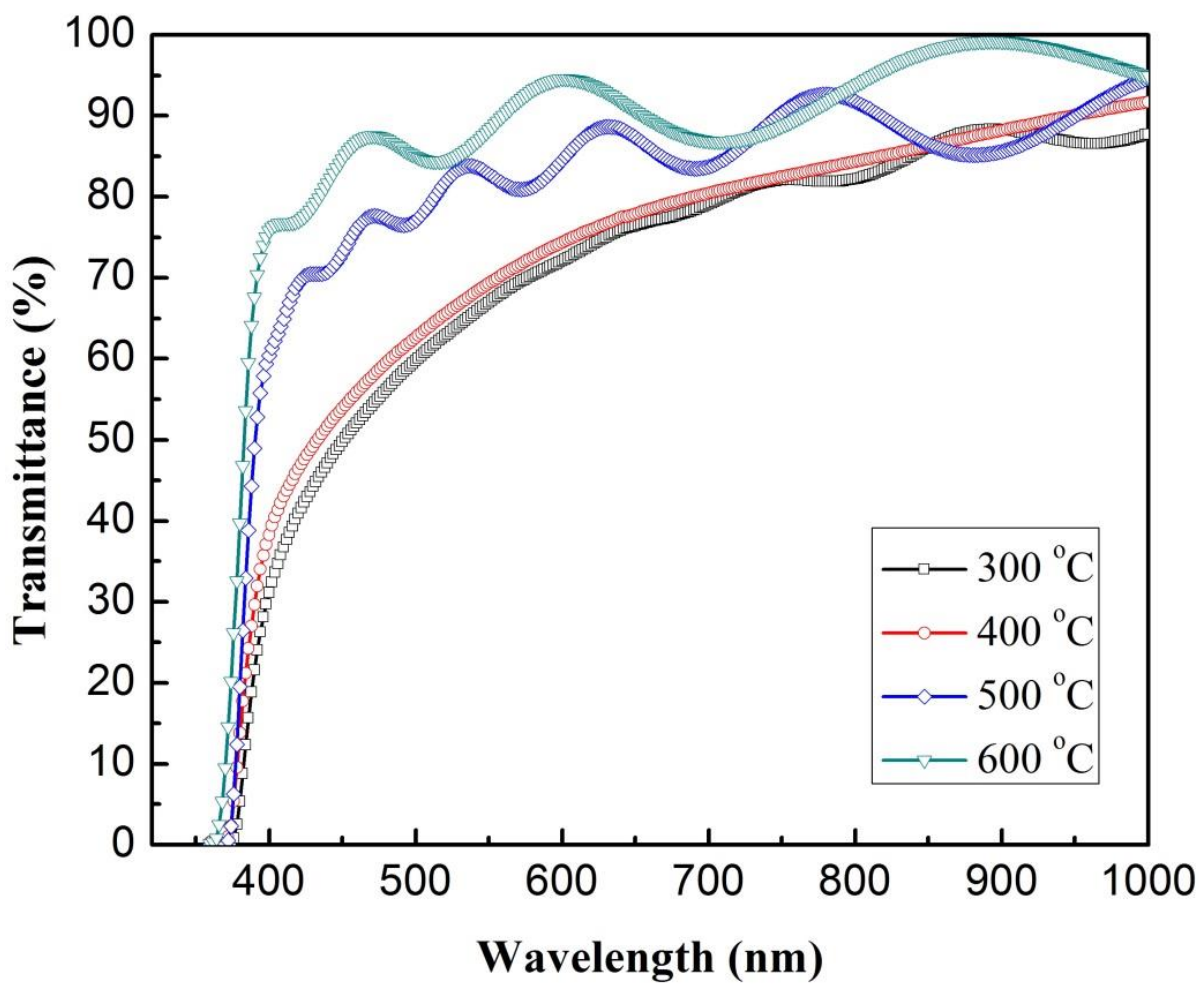

الثكل (4): يوضح تغير طيف النفاذية الضوئية لأغثية (ZnO) عذد درجات حرارة ترسيب مختلفة.

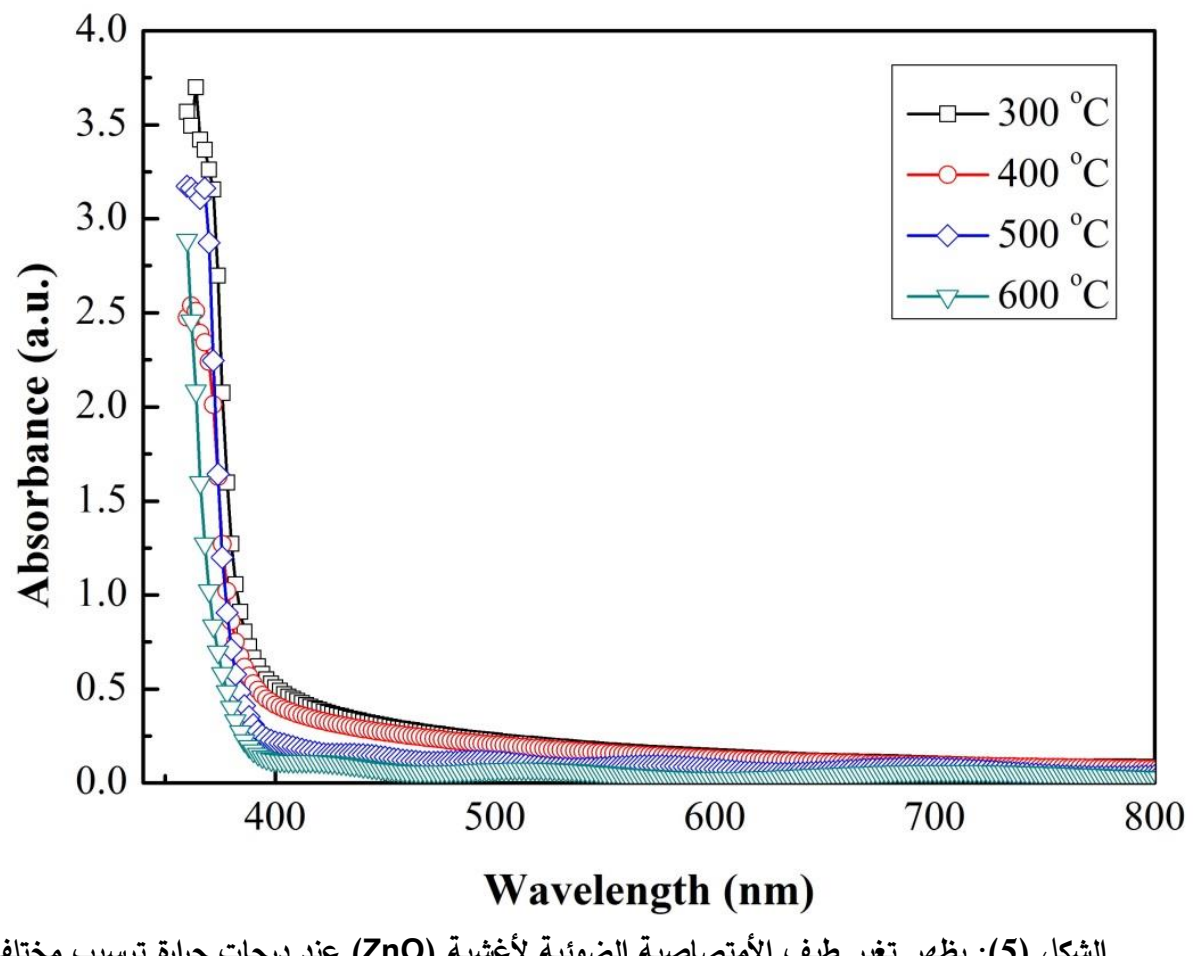

الثكل (5): يظهر تغير طيف الأمتصاصية الضوئية لأغشية (ZnO) عذد درجات حرارة ترسيب مختلفة. 


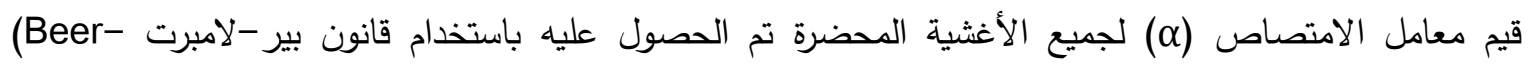
Lambert Law)

$$
\alpha=\frac{1}{\mathrm{t}} \ln \left(\frac{1}{\mathrm{~T}}\right)
$$

حيث ان (t) سمك الغشاء و (T) نفاذية الغشاء الرقيق. فجوة الطاقة البصرية (Ept) للأغشية الرقيقة تم حسابها باستخدام علاقة توك (Tauc’s relation)

$$
\alpha h v=A\left(h v-E_{g}\right)^{n}
$$

حيث ان (h) ثابت بلانك، (U) تردد فوتون الضوء الساقط، (A) ثابت يعتمد على قيمتي الكتلة الفعالة لحاملات الثحنة. الأس يعتمد على طبيعة الانتقالات البصرية السائدة. للانتقالات الأكترونية المباشرة المسموحة، غير المباشرة المسموحة والمباشرة الممنوعة، قيمة n تساوي (1/2)، (2) و (3/2) على التوالي. اظهرت نتائج العمل الحالي أن أغشية (ZnO) تمتلك انتقالات

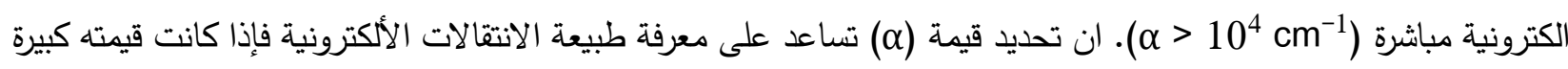

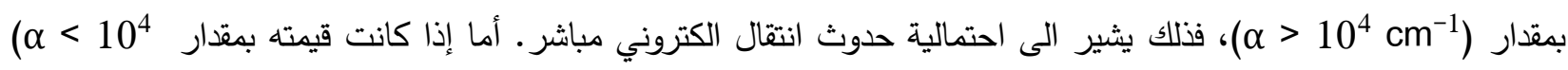

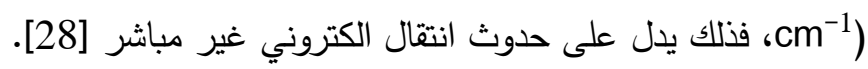
الثكل (6) يوضح العلاقة بين (hhv) و (hv) لأغشية (ZnO) الرقيقة المحضرة عند درجات حرارة ترسيب مختلفة. ان قيمة فجوة الطاقة البصرية للأغشية المحضرة ازدادت من (3.26 eV) الى (3.35 eV) مع زيادة درجة حرارة الترسيب من

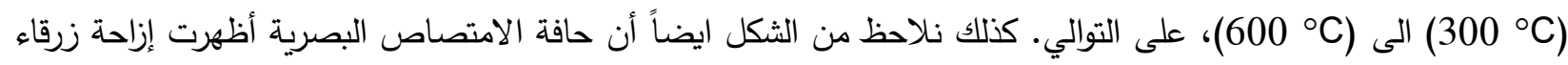
(Blue-Shift). إن زيادة فجوة الطاقة البصرية للأغثية المحضرة مع زيادة درجة حرارة الترسيب يمكن ملاحظته بوضوح في الجدول (1) و الثكل (7)، ويمكن أن تعزى هذه الزيادة الى تأثير بورشتن-موس (Burstein-Moss effect) [23]. 

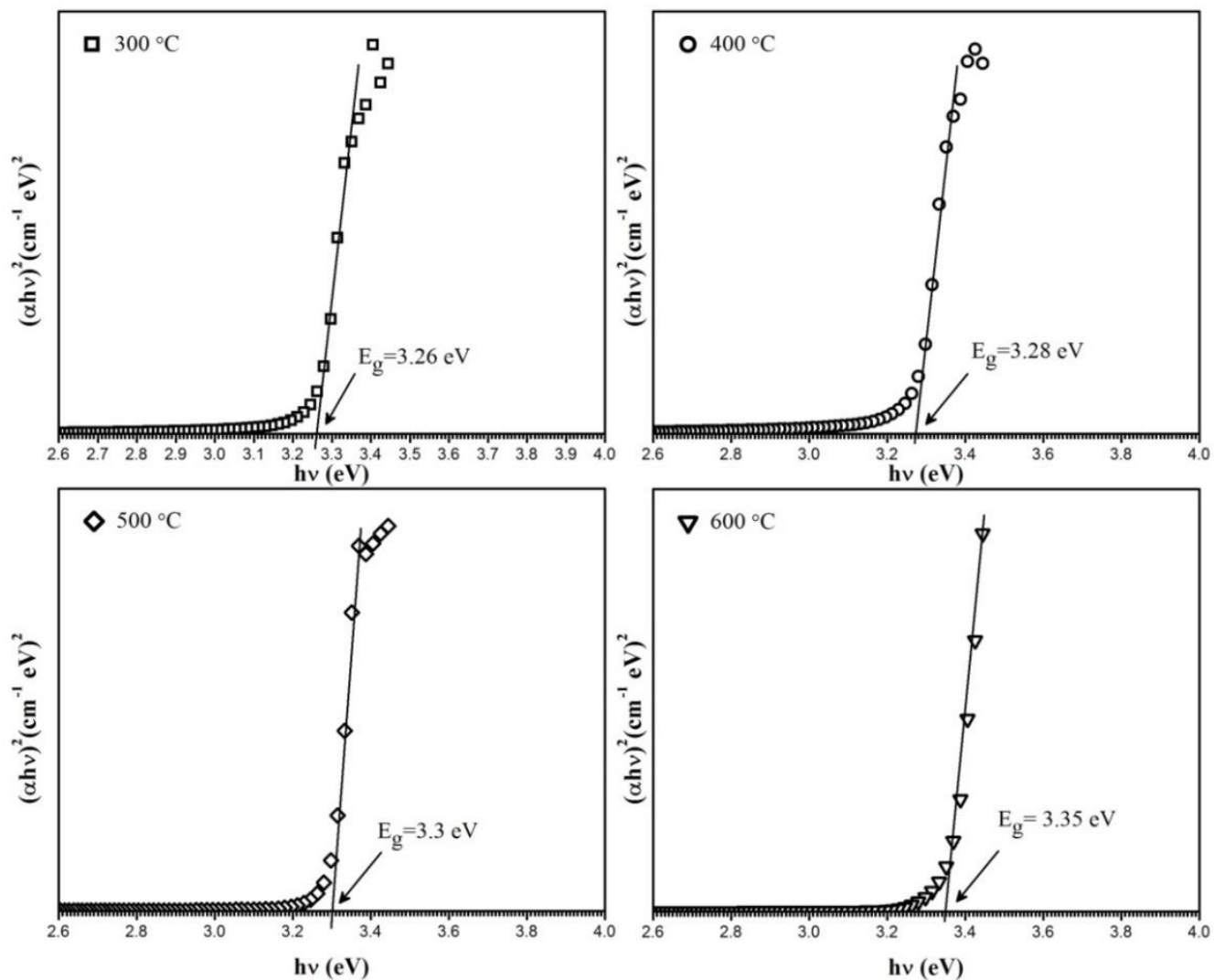

الثكل (6): العلاقة بين (hhv) و (hv) لأغثية (ZnO) الرقيقة المحضرة عذد درجات حرارة ترسيب مختلفة.

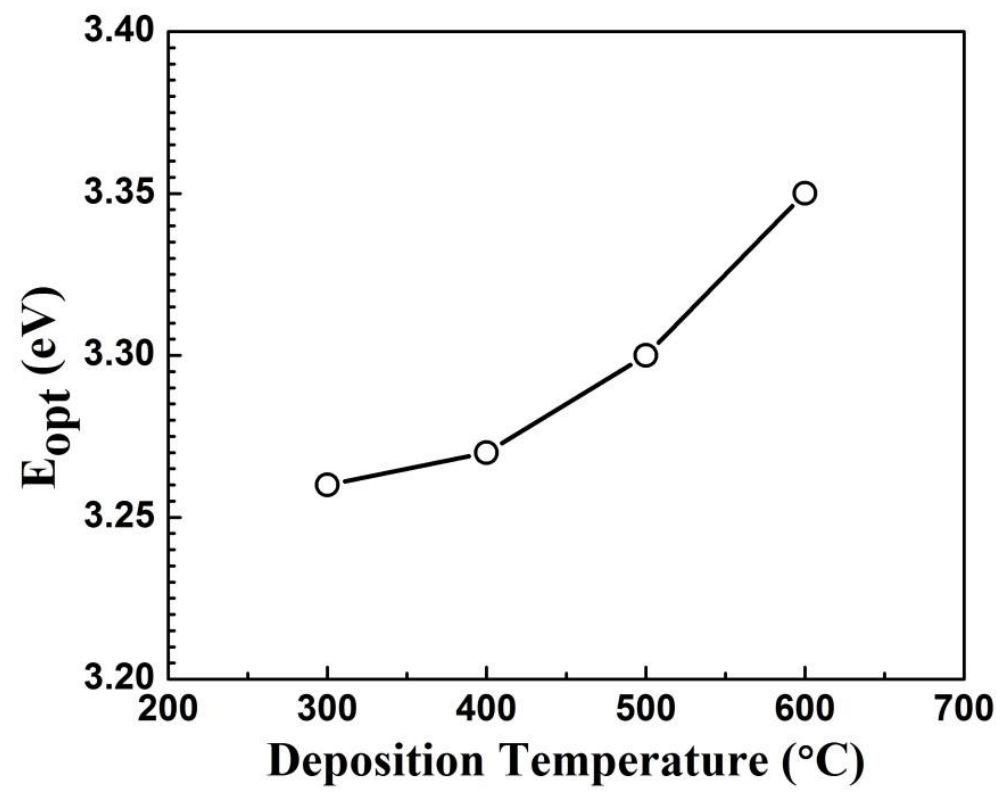

الثكل (7): العلاقة بين فجوة الطاقة البصرية ودرجة حرارة الترسيب لأغثية (ZnO).

الثكل (8) يظهر أطياف الأنعكاسية الضوئية لأغشية (ZnO) الرقيقة المحضرة عند درجات حرارة ترسيب مختلفة. نلاحظ من الثكل أن الأنعكاسية الضوئية للأغشية الرقيقة في المنطقة المرئية ومنطقة الاشعة تحت الحمراء تتغير أيضاً مع تغير

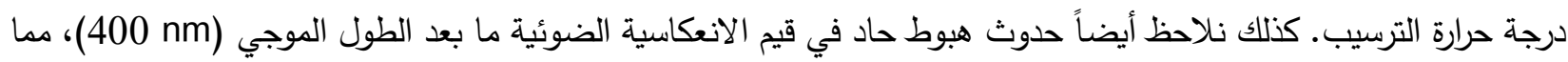
يثير الى وجود انتقالات ضوئية داخل فجوة الطاقة [16]. إن قيم الأنعكاسية الضوئية للأغشية تم حسابها باستخدام العلاقة الآتية 
$\mathrm{R}=1-\mathrm{T}-\mathrm{A}$

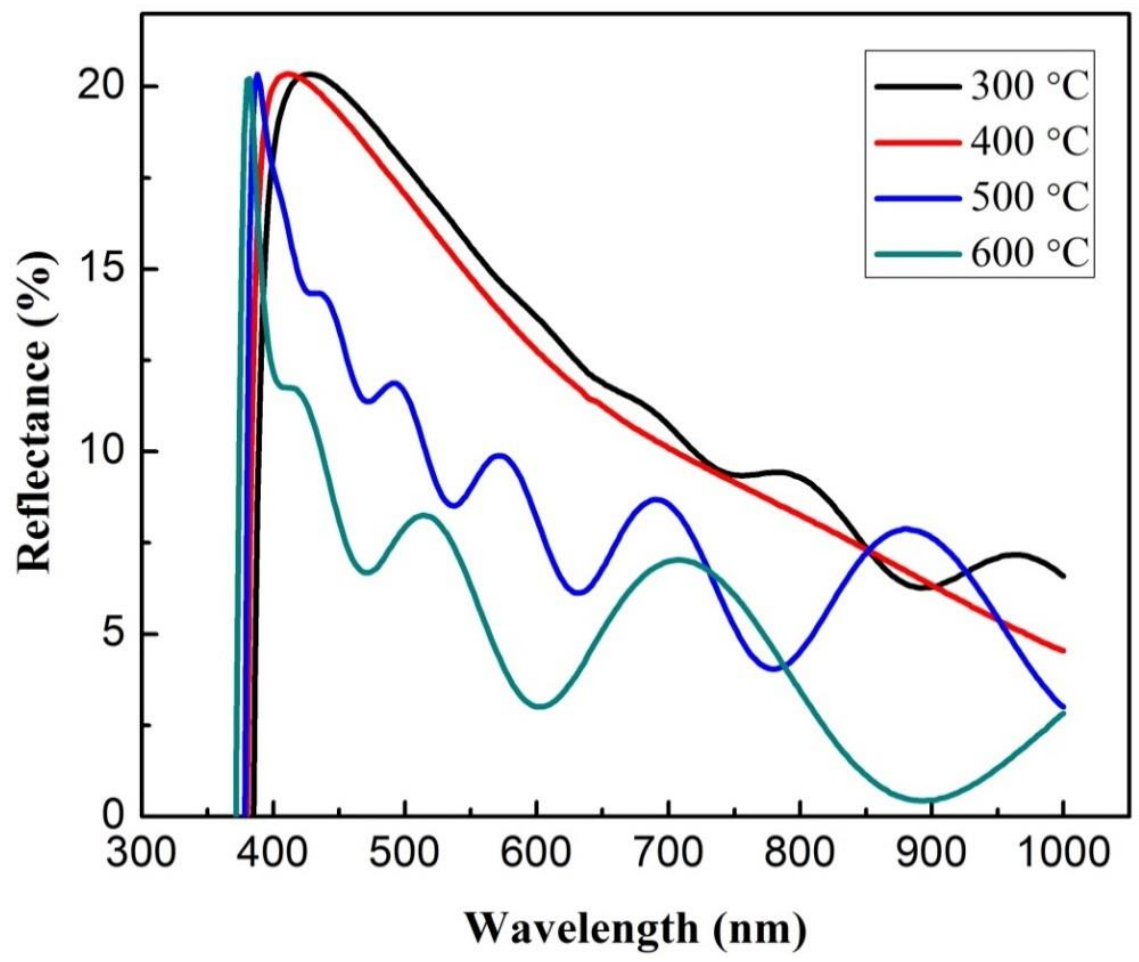

الثكل (8): يعرض تغير طيف الأنعكاسية الضوئية لأغثية (ZnO) عند درجات حرارة ترسيب مختلفة.

الثكل (9) يظهر خصائص تيار - فولتية للثنائيات المتباينة المقاسة في حالة الظلام. اظهرت الثنائيات المتباينة سلوكاً غير مثالي، والذي قد يكون بسبب وجود حالات سطحية، طبقة الأوكسيد والطبيعة البلورية لأغثية اوكسيد الزنك [30].

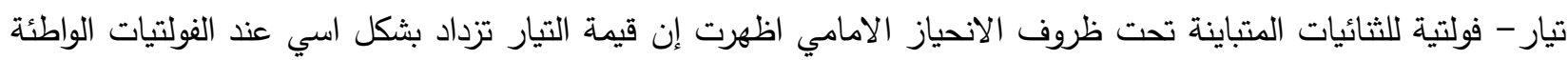

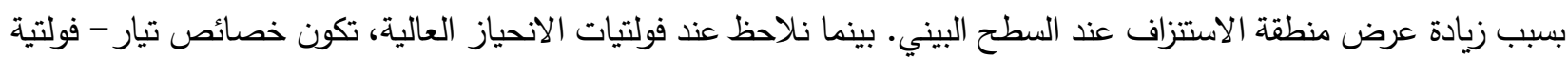
خطية تقريباً وذلك لأن طبقة الاستتزاف تقل عند السطح البيني [30]. من الواضح أن نسبة التقويم Rectification Ratio) (RR)) هذا بالحجم الحبيبي لأغشية ZnO [30]. ان ارتفاع قيمة RR، يثير الى تحسن أداء الثنائي المتباين. للحصول على معلمات

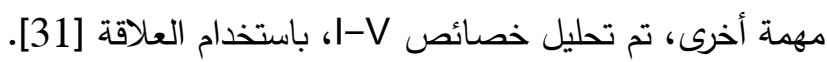

$I=I_{o} \exp \left(\frac{q V_{d}}{\eta k T}\right)$

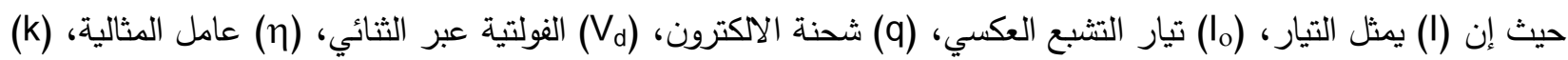

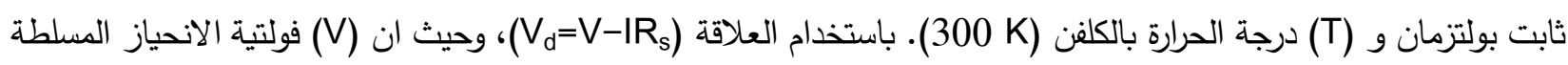

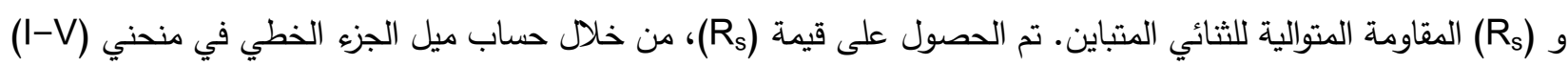

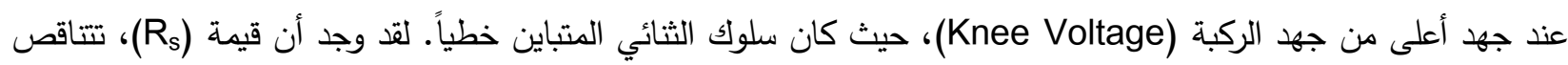

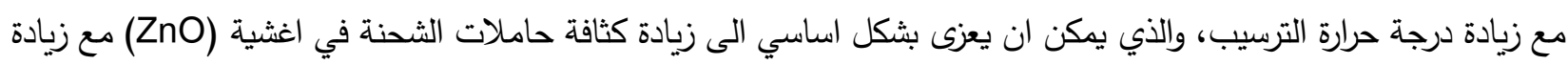

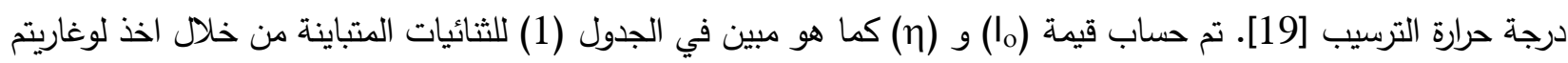




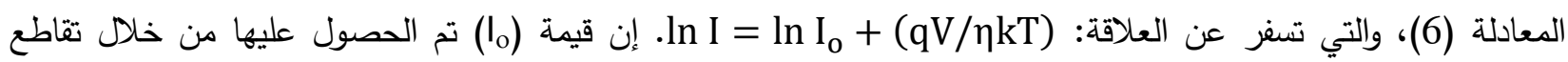

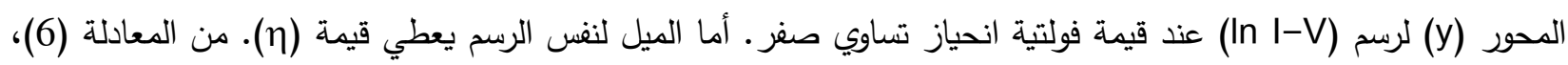

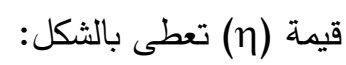

$\eta=\left(\frac{\mathrm{q}}{\mathrm{kT}}\right)\left(\frac{\partial \mathrm{V}}{\partial \ln \mathrm{I}}\right)$

من الجدول (1)، وجد أن عند زيادة درجة حرارة الترسيب، ازدادت قيمة تيار التشبع العكسي. تم ملاحظة سلوك مماثل

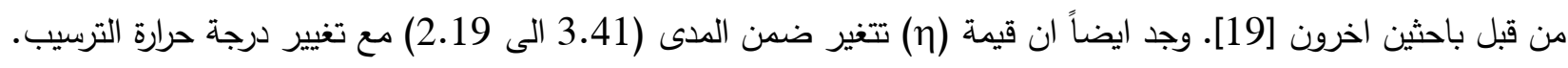

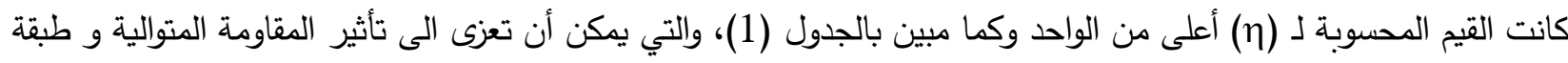

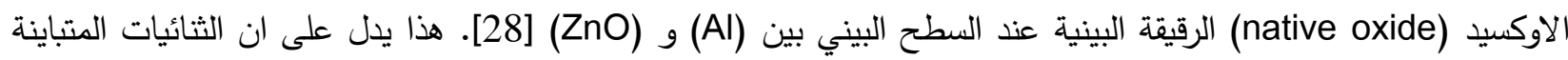

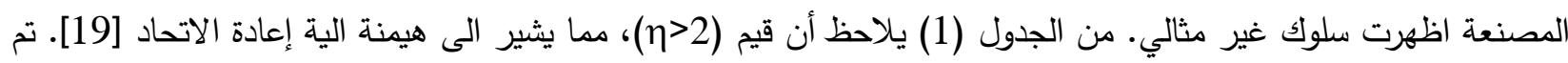

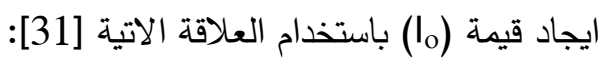

$\mathrm{I}_{\mathrm{o}}=\mathrm{AA}^{*} \mathrm{~T}^{2} \exp \left(-\frac{\mathrm{q} \phi_{\mathrm{b}}}{\mathrm{kT}}\right)$

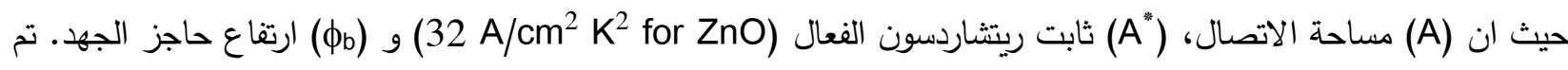

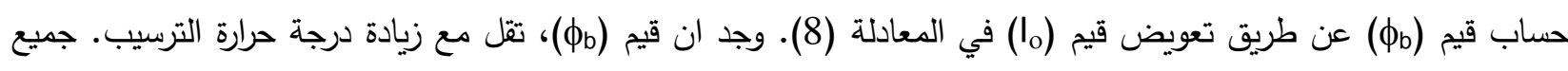

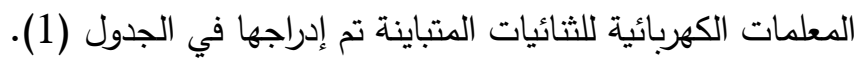

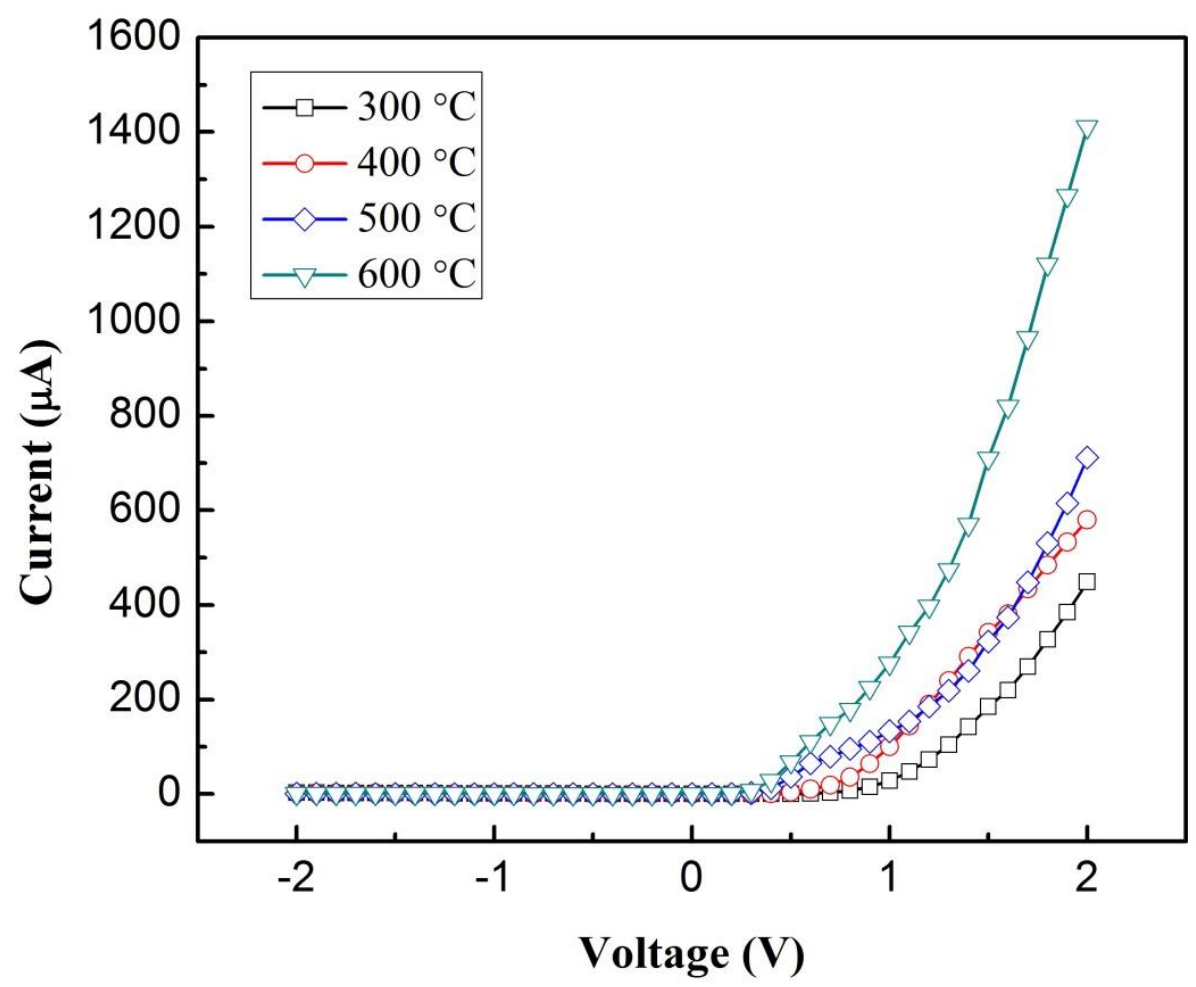

الثكل (9): يعرض خصائص تيار - فولتية للثنائيات المتباينة المحضرة عند درجات حرارة ترسيب مختلفة. 
الاستتاجات

باختصار، تم ترسيب جميع أغشية (ZnO) الرقيقة على أرضيات من الزجاج والسليكون (p-Si) باستخدام تقنية ضمن مدى درجات الحرارة (APCVD) المورفولوجية والضوئية لأغشية (ZnO) الرقيقة ومن ثم تحديد تأثيرها على اداء المفرق المتباين (n-ZnO/p-Si) باستخدام

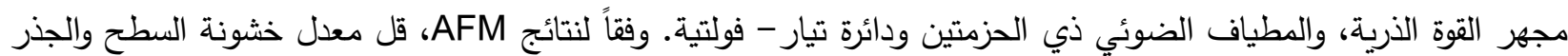
التربيعي لمربع متوسط الخشونة وكذلك انخفاض عدد الفراغات على سطح الغشاء الرقيق مع زيادة درجة حرارة الترسيب. لقد تبين أنه من خلال السيطرة على درجة حرارة الترسيب، يمكن التحكم في حافة امتصاص الأشعة فوق البنفجية، ويمكن التحكم ايضاً

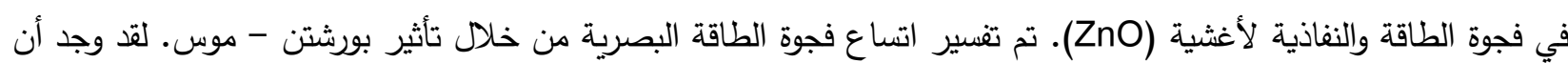

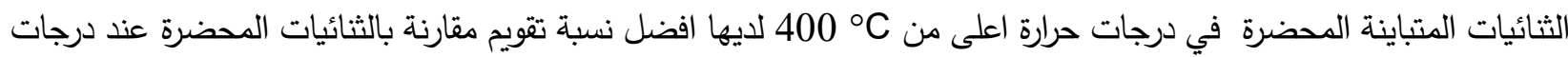
حرارة أقل من Co C

\section{Acknowledgments}

The author is gratefully acknowledges the partial financial support from Ministry of Higher Education and Scientific Research, Iraq.

1 Fan, Z. and Lu, J. G., Journal of Nanoscience and Nanotechnology, 5(10) 1561-1573 (2005)

2 Özgür, Ü., Alivov, Y. I., Liu, C., Teke, A., Reshchikov, M. A., Doğan, S., Avrutin, V., Cho, S.-J. and Morkoç ,H., Journal of Applied Physics, 98(4) 041301 (2005)

3 Choi, Y., Kang, J., Hwang, D. and Park, S., IEEE Transactions on Electron Devices, 57(1) 26-41 (2010)

4 Faÿ, S., Steinhauser, J., Nicolay, S. and Ballif, C., Thin Solid Films, 518(11) 2961-2966 (2010)

5 Fernández, S. and Naranjo, F. B., Solar Energy Materials and Solar Cells, 94(2) 157-163 (2010)

6 Yamamoto, N., Makino, H., Osone, S., Ujihara, A., Ito, T., Hokari, H., Maruyama, T. and Yamamoto, T., Thin Solid Films, 520(12) 4131-4138 (2012)

7 Echresh, A., Chey, C. O., Zargar Shoushtari, M., Khranovskyy, V., Nur, O. and Willander, M., Journal of Alloys and Compounds, 632 165-171 (2015)

$8 \quad$ Klingshirn, C., physica status solidi (b), 244(9) 3027-3073 (2007)

9 Adamopoulos, G., Bashir, A., Wöbkenberg, P. H., Bradley, D. D. C. and Anthopoulos, T. D., Applied Physics Letters, 95 (13) 133507 (2009)

10 Jagadish, C. and Pearton, S. J., "Zinc Oxide Bulk, Thin Films and Nanostructures: Processing, Properties and Applications". New York, Elsevier, (2006) 
11 Echresh, A., Ali Abbasi, M., Zargar Shoushtari, M., Farbod, M., Nur, O. and Willander, M., Semiconductor Science and Technology, 29(11) 115009 (2014)

12 Chen, T., Liu, S.-Y., Xie, Q., Detavernier, C., Van Meirhaeghe, R. L. and Qu, X.-P., Applied Physics A, 98(2) 357 (2009)

13 Henley, S. J., Ashfold, M. N. R. and Cherns, D., Surface and Coatings Technology, 177178(Supplement C) 271-276 (2004)

14 Heo, Y. W., Norton, D. P. and Pearton, S. J., Journal of Applied Physics, 98(7) 073502 (2005)

15 Li, X.-Y., Li, H.-J., Wang, Z.-J., Xia, H., Xiong, Z.-Y., Wang, J.-X. and Yang, B.-C., Optics Communications, 282(2) 247-252 (2009)

16 Mohammed, Y. H., Superlattices and Microstructures, 131 104-116 (2019)

17 Xiang, B., Wang, P., Zhang, X., Dayeh, S. A ,.Aplin, D. P. R., Soci, C., Yu, D. and Wang, D., Nano Letters, 7(2) 323-328 (2007)

18 Pierson, H. O., "Handbook of Chemical Vapor Deposition: Principles, Technology and Applications". New Jersey, NOYES PUBLICATIONS, (1999)

19 Sahu, V. K., Misra, P., Ajimsha, R. S., Das, A. K. and Singh, B., Materials Science in Semiconductor Processing, 54 1-5 (2016)

20 Zhang, Z., Bao, C., Yao, W., Ma, S., Zhang, L. and Hou, S., Superlattices and Microstructures, 49(6) 644-653 (2011)

21 Eckertová, L., "Physics of Thin Films". New York, Springer US, (1977)

22 Shiau, J.-S., Brahma, S., Liu, C.-P. and Huang, J.-L., Thin Solid Films, 620(Supplement C) 170-174 (2016)

23 Chen, H., Ding, J., Guo, W., Shi, F. and Li, Y., Applied Surface Science, 258(24) 99139917 (2012)

24 Ramakrishna Reddy, K. T. and Miles, R. W., Journal of Materials Science Letters, 17(4) 279-281 (1998)

25 Yahya, N., "Carbon and Oxide Nanostructures: Synthesis, Characterisation and Applications". New York, Springer Berlin Heidelberg, (2011)

26 Lemlikchi, S., Abdelli-Messaci, S., Lafane, S., Kerdja, T., Guittoum, A. and Saad, M., Applied Surface Science, 256(18) 5650-5655 (2010)

27 Kasap, S. and Capper, P., "Springer Handbook of Electronic and Photonic Materials". NewYork, Springer, (2006)

28 Soylu, M. and Savas, O., Materials Science in Semiconductor Processing, 29(Supplement C) $76-82(2015)$ 
29 Stenzel, O., "The Physics of Thin Film Optical Spectra: An Introduction", Springer International Publishing, (2015)

30 Singh, S. K. and Hazra, P., Journal of Materials Science: Materials in Electronics, 29(6) 5213-5223 (2018)

31 Sze, S. M., "Physics of Semiconductor Devices", John Wiley and Sons, (1981) 